\title{
Claims Solutions Using a Blockchain System in International Logistics
}

\author{
Nijolè Batarliené *(D) and Maksimas Meleniakas
}

Citation: Batarlienè, N.;

Meleniakas, M. Claims Solutions Using a Blockchain System in International Logistics. Sustainability 2021, 13, 3710. https://doi.org/ $10.3390 /$ su13073710

Academic Editor: Vittorio Checchi

Received: 5 February 2021

Accepted: 23 March 2021

Published: 26 March 2021

Publisher's Note: MDPI stays neutral with regard to jurisdictional claims in published maps and institutional affiliations.

Copyright: (c) 2021 by the authors. Licensee MDPI, Basel, Switzerland. This article is an open access article distributed under the terms and conditions of the Creative Commons Attribution (CC BY) license (https:/ / creativecommons.org/licenses/by/ $4.0 /)$.
Department of Logistics and Transport Management, Faculty of Transport Engineering, Vilnius Gediminas Technical University, 10223 Vilnius, Lithuania; maksimasmeleniakas@gmail.com

* Correspondence: nijole.batarliene@vilniustech.lt; Tel.: +370-5-2370-634

\begin{abstract}
A claim can be understood as a negative result of the performance of a contract, as it is necessary to fulfill the obligation and/or indemnify (freight damage claim, for example). Today's claims management faces a variety of problems, such as inefficient claims postings, possible data forgery, and a very lengthy claims resolution process. All these problems can be solved by using a synthesis of innovative tools, e.g., a blockchain system, game theory, and statistical methods. Theoretical possibilities and practical examples regarding solving claims management problems were identified by analyzing various scientific sources. However, it remained unclear whether these methods could interact with each other, complicate the existing claims settlement process or not, or whether a synthesis of such measures would be viable. Therefore, a qualitative study was conducted and answers to the above questions were found. The research revealed that $75 \%$ of international Lithuanian logistics companies can apply the synthesis of these methods in claims management and solutions. Using the concordance coefficient formula, the value of $W$ was calculated. This coefficient indicated that the opinions of the experts who participated in the study were somewhat similar. The value of the actual $\chi^{2}$ distribution was also calculated. The result obtained shows that the experts' opinions were somewhat harmonized and that their compatibility was not accidental. The use of blockchain system synthesis in combination with game theory and statistical methods could help international logistics companies to reduce their costs, speed up the management process, and increase data security and reliability while ensuring structured one-stop claims management.
\end{abstract}

Keywords: blockchain system; game theory; statistical methods; claims management; international logistics

\section{Introduction}

Logistics can be defined as "part of the supply chain process that plans, implements and controls the flow and storage of goods and services between the point of origin and the point of consumption to meet customer's requirements" [1]. In other words, the principle of logistics is "to deliver the right products to customers, at the right time, with the right quality, in the right place and at the right price" [2].

Losses and damage sometimes occur during freight transportation. In such cases, transport managers make claims against carriers to compensate for part or all of the damage suffered. Transport companies are responsible for all losses, damage, and delays in freight transport. Customers who have received damaged goods can demand compensation from the seller (carrier), and if they refuse to pay it, they can file a claim with the seller.

Claims are a phenomenon that is part of the business, as they can be made by both customers and employees, and their solution is usually individual and unsystematic. Claims in logistics (freight damage claims, for example) are not uncommon since, in these activities, the number of processes with variable factors is the basis of the activity and unique situations constantly occur. The claimant must prove that the carrier has tampered with the vehicle or container, which has caused damage to the cargo due to unsafe transport. 
In order to prove this, it is necessary to perform an examination of the cargo and a technical inspection of the vehicle or container.

Current business requires a constant flow of new ideas [3], approaches, and solutions to keep pace with accelerating change and uncertainty. Logistics itself is carried out in a space that is constantly changed by geographical, natural, political, legal, economic, security, technological, qualitative, quantitative, pricing, and tariff factors [4]. Therefore, in order to achieve high-quality indicators in logistics, it is necessary to ensure four main processes: problem "extinguishing", auditing, process improvement, and delegation [5]. These processes have a direct connection with the number of claims in international logistics because if they are not properly executed, the terms of the international logistics contract may be violated due to the influence of all the listed factors.

Today, there are several well-established management techniques that can help companies meet the demands of claims. However, ways still need to be found to meet the new opportunities offered by modern knowledge and technology. For a modern claims solution, the blockchain system and the principles it provides must be used. All this can show great synergies in the whole modern international logistics business [6,7], especially in claims handling, as managers from all over the world share good practices in order to develop the maximum work competence [8].

The blockchain system is an important technology for records management professionals to understand because it has broad implications for securing and authenticating intellectual property at a lower cost and higher efficiency. The blockchain is a distributed database of records of all transactions or digital events that have been executed and shared between participating parties.

The blockchain system was first published in 2008 [9] and is one of the latest technological breakthroughs that can fundamentally change the perception and performance of various processes.

Although the blockchain is mainly related to bitcoins, its principle can be applied in practice in other areas that deal with operations or share records. The blockchain system is a digital mechanism that allows you to perform reliable operations.

The blockchain system is the "leading technology" [10] today. According to researchers, by 2022 , more than $25 \%$ of all global companies in the supply chain will use the blockchain system [11]. This system can be particularly useful, as there is no possibility of falsifying the transaction history [12]. According to current logistics and transport estimates, $10 \%$ of all consignment notes contain inaccurate data (e.g., shipping costs); the blockchain system can reduce this percentage [13]. The application of the blockchain system in logistics is expected to provide an advantage in terms of inherent technological features, such as transparency, consistency, and decentralization. Brand [1] defines international logistics as a part of the supply chain that involves fewer processes than the entire supply chain.

The literature states [14-18] that people's mood, social environment, and other similar factors influence firms' decisions and, subsequently, firms' profits. Therefore, it can be argued that behavioral economics tools, such as game theory, and the synthesis of statistical methods with the blockchain system may provide an advantage over the currently used methods for claims management in international logistics.

The problem considered in this article is that it is not known to what extent international logistics companies use game theory and the synthesis of statistical methods with the blockchain system and whether they are interested in the technological development of claims management. Therefore, during the study, we will try to answer two specific questions:

- What are the possibilities of applying blockchain technology in international logistics for resolving customers' claims?

- Is it possible to link blockchain technology to game theory and the use of statistical methods in international logistics? 
The aim of this article was to present the possibilities of applying the blockchain system, together with game theory and statistical methods, to find out whether these methods can interact with each other and whether the synthesis of such tools is promising for solving claims in international freight transport. To achieve this goal, possible scenarios of blockchain application for and in international logistics for solving claims are identified, thus providing not only a theoretical basis for blockchain technology but also synthesizing and highlighting real application possibilities.

\section{Blockchain for and in International Logistics Claims Management}

The blockchain system is an innovative element as it is a fairly new technology and is increasingly being integrated into many business processes.

The blockchain system is often described as "a distributed, decentralized, public ledger" [19]. This includes the retrieval and storage of digital information ("block") in a public, decentralized database ("chain"). The block provides basic information about the transaction, the parties involved in it, and what sets this transaction apart from others.

International logistics is part of the supply chain and therefore involves fewer processes than the entire supply chain [20]. Figure 1 shows a supply chain model and an example of how a blockchain system works (according Volkmar-Jaeger and SebastianHok [21]).

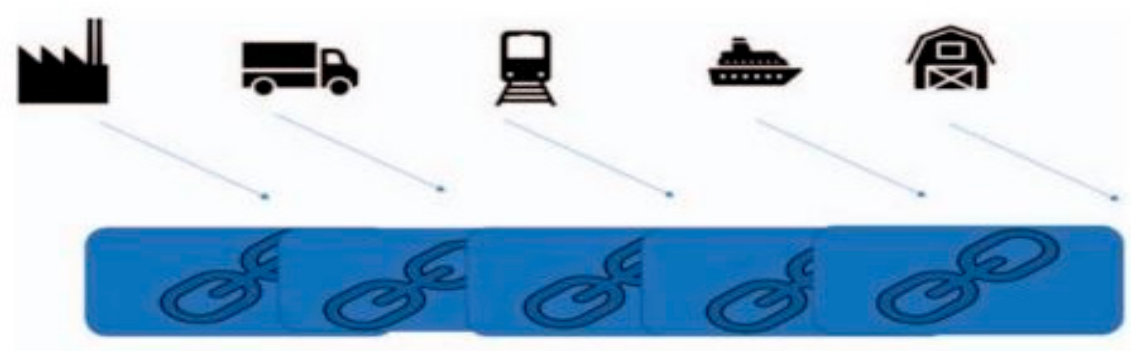

Figure 1. Example of a blockchain's system operations in the supply chain.

It can be seen from Figure 1 that, by entering important data into the blockchain system after each stage of cargo transportation, it will be possible to avoid falsification or delay of the claim or, at best, to avoid claims through prevention (e.g., pre-inspection and validation of data, labels, and documents, as well as using a services supply price formula) [22].

An important aspect of the blockchain system is the benefits of this system for any transport and logistics company or any business organization. Table 1 lists five key benefits of the blockchain system [23].

Table 1. Advantages of the blockchain system.

\begin{tabular}{cl}
\hline Advantages for Transport Management & \multicolumn{1}{c}{ Advantages of the Blockchain System } \\
\hline Cost reduction & Processes become more efficient and cheaper. The number of intermediaries is decreased. \\
Efficiency & A smaller number of intermediaries allows for performing the operation in seconds. \\
Safety & A smaller number of intermediaries reduces vulnerability. \\
Flexibility & Any digital device can use the blockchain system. \\
Competitive advantage & With this system, companies can offer new services that will benefit both buyers and content creators. \\
\hline
\end{tabular}

Table 1 lists the general benefits of using the blockchain system. These benefits will be independent of the activities of the transport company that will implement this blockchain system; therefore, it is necessary to determine whether there are any specific benefits of implementing this system in the supply chain.

Table 2 shows the benefits of the blockchain system in the supply chain (according to Manners-Bell and Lyon [13]). 
Table 2. Advantages of the blockchain system in the supply chain.

\begin{tabular}{cl}
\hline No. & \multicolumn{1}{c}{ Advantages of the Blockchain System in the Supply Chain } \\
\hline 1. & Absolute transparency. \\
2. & Data sustainability and integrity of operations throughout the supply chain. \\
3. & Availability for an unlimited number of participants. \\
\hline
\end{tabular}

The benefits in Table 2 can be compared to the overall benefits of the blockchain system in Table 1. In this case, it becomes clear that the overall advantage is this: by using the blockchain system, the cost reduction will be independent of the specialized use of this system. Thus, with the blockchain system, an improvement in eight indicators can be expected.

More safety information is also available on the blockchain system [24]. The authors state that each block is entered into a common list of blocks and is transmitted in only one copy with a block check timestamp.

The blockchain system helps to improve the traceability of freight trade flows [25]. The blockchain system is relevant for operations, such as the cross-border authentication of goods and services, as well as data operations. This is relevant for logistics services and companies in various modes of transport [26]. The blockchain system can help to safely transport high-value goods and goods that are easily counterfeited, such as pharmaceuticals and medical goods. There are cases in the literature where the blockchain system is used in the diamond supply chain [27] and the blockchain system has been adopted in airports [28] and seaports [29]. The blockchain system has been used in the context of the food supply chain to highlight the key challenges of designing and implementing a blockchain and to provide a strategic assessment of its prospects [30].

These days, in practice and academically, blockchain technology is a controversial concept [31-33]. The concept at issue is that different stakeholders have their own definitions, perspectives, and definitions of the blockchain and its elements.

The blockchain system can also be applied in environmental practice [34]. Blockchain technology supports component identification throughout a product's life cycle. Blockchain technologies can be adapted to determine the value of optimal service pricing under a common pricing policy strategy based on the client's risk approach [35]. The customer risk approach plays a crucial role in determining the optimal demand for services on demand, where blockchain technology is a valuable technological tool.

In order to understand the benefits of the blockchain system and the possibilities of applying it in claims resolution, it is necessary to know the objectives of claims management. It is stated that there are two fundamental goals in claims management:

1. Identify deviations between the current and contractual target status, along with the requirements arising from these deviations.

2. Prevention of claims or fulfillment of a contract partner's conditions [36].

From these objectives, we see that in the case of a claim, discrepancies with the existing contract need to be identified. In international logistics, such contracts can take many forms, for example, between a carrier and a freight forwarder, or between a freight forwarder and warehousing companies.

In the business world, each company has the opportunity to set a personal strategy direction for its operations [37]. One such strategy is a knowledge-based business management strategy that commits to learning from organizational processes [38]. By analyzing a process, such as claims management and business contract breaches, it is possible to accumulate and systematize the resulting knowledge and data. Various data are very important for every company and this can be clearly seen [39].

Claims are an important part of the customer service department [40]. A claim can be understood as a negative result of the performance of the contract, as it is necessary to fulfill the obligation and/or indemnify. 
The action of claim decision management is usually understood as the solution to some existing problem [41]. Claims management is one of the areas of management. The business claims management model [42] is presented in Figure 2.

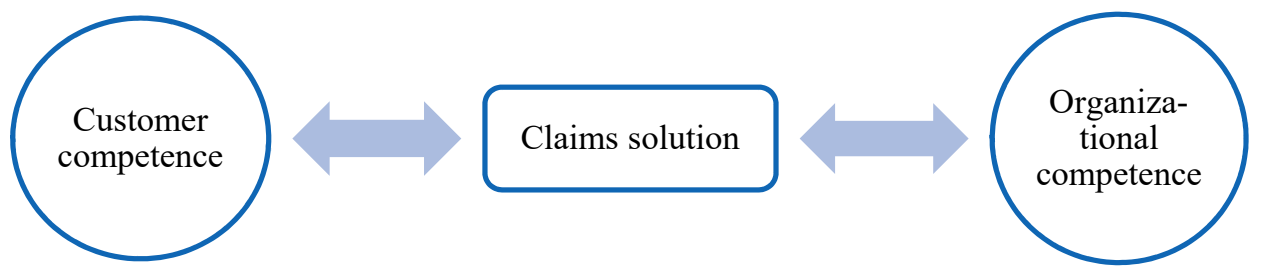

Figure 2. Business claims resolution model.

Competence is the deciding factor when considering claims. However, competence in business can cover so many different things and details that in order to successfully deal with claims, one needs to find out and know these things accurately.

The 2PL (Second-Party Logistics), 3PL (Third-Party Logistics) and 4PL (Fourth-Party Logistics) models are most commonly used to organize international shipments. In these models, one of the necessary players is the freight carrier (transport company). Given its necessity, the carrier must provide evidence that could rebut this presumption of guilt and prove what happened. Blockchain technology can do this.

Many project managers state that in claims management, preparing for negotiations requires the most time and energy [6]. Claims management is one of the types of management that is relevant in international logistics and is being improved by developing various models [43]. The value of mathematical analysis in solving claims can be determined based on a study by Malaysian contractors in construction projects, which stated that solving complex problems requires planning, mathematical modeling, problem perception, and other components more than experimentation, questioning, discussion, etc. [44].

The blockchain system is useful in international logistics. This system has the following features:

- It consists of information (blocks).

- It is public and decentralized.

- The information in the blocks maintains the details of the transaction, the parties involved, and the unique information that distinguishes the block from others [45].

The blockchain system takes the place of an innovative element as it is a fairly new technology and is increasingly being integrated into many business processes [46]. The blockchain system is already used to register services, such as when issuing a driver's license or when police officers need to see all relevant data without providing them with a driver's license and other documents. Obviously, this system helps to solve management tasks and can be perfectly adapted to solve claims.

Table 3 presents the different aspects of claim resolution by Johnson [47] and Greenhalgh [48].

Table 3. Aspects of claims resolution.

\begin{tabular}{|c|c|}
\hline Johnson [47] & Greenhalgh [48] \\
\hline $\begin{array}{l}\text { Determine when to start claims resolution } \\
\text { processes and how to develop them. }\end{array}$ & Planning is needed. \\
\hline $\begin{array}{l}\text { Take into account all factors related to the claims. } \\
\text { Manage negotiation processes. } \\
\text { Identify and use strategies to best deliver claims. } \\
\text { Maintain control over negotiation processes. }\end{array}$ & $\begin{array}{l}\text { Constructive logic is needed. } \\
\text { Start and end date settings are required. } \\
\text { Restraint is needed. }\end{array}$ \\
\hline
\end{tabular}

The aspects of claims decisions presented in Table 3 are, in principle, similar and complementary. Johnson focuses on managerial approaches in his claims resolution aspects, 
while Greenhalgh focuses more on the behavior of the claims officer. It is believed that international logistics companies facing claims decisions can follow these rules in their daily work or supplement the job descriptions of specialists. In this case, the company will ensure that the regularity of the claims resolution process is documented.

The application of international logistics laws and international agreements in resolving claims is not the same in every country [49]. There are two types of claims:

1. Claims against national relations shall be governed by national law.

2. Claims against international relations shall be settled using the Convention on the Contract for the International Carriage of Goods by Road (CMR Convention) or other ratified international agreements.

According to Jung and Krebs [36], several main strategies in claims management are distinguished:

- Passive claims strategy.

- Defensive claims strategy.

- Aggressive claims strategy.

Summarizing the strategies described by these authors [36], it becomes clear that claims management strategies are particularly important for international logistics companies, as international logistics is rarely organized using the 1PL model (the 1PL model is the case where the cargo owner themself is engaged in logistics). In all other cases, the international logistics process involves various actors who pursue their goals.

Each action requires different resources. Robinson [50] provided a list of the most timeconsuming actions that are performed in resolving claims. These are damage calculations, repair pricing, claims preparations, filling in documents, etc.

International claims, according to Robinson [41], can be divided into two main groups:

1. Claims related to infrastructure.

2. Claims related to finance.

This division can be detailed based on Richards and Grinsted [51], who provided a list of key international logistics processes that can be used as a tool for segmenting internal claims in international logistics. The list is as follows:

1. Transport audit.

2. Calculation of emissions in freight transport.

3. Fuel adjustment factor formula.

4. Improving fuel efficiency.

5. Incoterms.

6. Loading and pallet configuration.

7. ISO containers (an international intermodal container that is manufactured according to the specifications outlined by the International Organization for Standardization (ISO), weight to volume ratios, pallets.

8. Calculation of freight charges and their levels.

9. Transport management system selection process.

10. Transport problems-compliance of customer demand with the supplier's capacity.

11. Ensuring the sales of transport logistics service providers.

12. Regulation of drivers' working time.

13. Transport of dangerous goods.

By analyzing scientific literature sources, it is possible to detect various suggestions on how to effectively prepare a claim. Such suggestions may include the need for simple text, a clear presentation of the facts, the need to prepare a summary, and a clear presentation of the method or formula for calculating the damage, together with other relevant data, when preparing claims $[21,39,48,50,52]$.

A scientific review of the literature has revealed that not all innovative solutions are applied in international logistics claims management. Of course, innovation is a process without an end. It is, therefore, necessary to research and apply the latest knowledge [53]. 
Reviewing the main aspects of innovative claims management methods [54-57], we can state that there are opportunities to improve the international logistics claims resolution process. The literature has examined the most important skills that are most needed when dealing with claims $[58,59]$. It can be assumed that the more experienced that the specialists in transport and logistics companies are, the more relevant new methods of business claims resolution are for them.

It is argued that "Blockchain will revolutionize business and redefine logistics" [4], and current research is limited to systems that distribute blockchain applications and their implications. The examined academic literature on transport and logistics does not sufficiently distinguish how to apply blockchain technology in international logistics, nor does it indicate the possibilities of how blockchain technology can help customer service.

\section{Materials and Methods}

In the international logistics business, claims are handled inefficiently because companies are unable to invent and absorb the latest knowledge and technology. It is very important that claims are accepted and resolved using the latest technology. Therefore, in order to achieve a high level of claims resolution, we propose to use modern knowledge synthesis: to link the blockchain system with game theory and statistical methods.

Each blockchain in the blockchain system is organized according to the following basic principles:

- Decentralization-data is not stored on a central server, but on the entire computer network.

- Openness - anyone can view the entries in a blockchain.

- Immutability - data stored in a blockchain cannot be altered or tampered with.

The invariance of a blockchain means that the data stored in the blockchain can never be changed. Such a feature would be very useful for transport and logistics companies and insurance companies, as it would reduce fraud or embezzlement. People would know that the system could not deceive. This unique feature of a blockchain is provided by the cryptographic hash function.

The hash function is a special encryption algorithm that converts input information of any size into a fixed-size encrypted code. The hash functions use various information coding algorithms.

Game theory is a new theory that can be applied to claims. This theory is described by various authors. Chadha [60] argues that game theory is designed to predict strategic thinking and human behavior. It has been argued that game theory can be defined as a mathematical model that examines the possibilities for cooperation and conflict between rational decision-makers [6]. From an economic point of view, this theory may be applied to the settlement of claims by setting the goals and rules of the game. The objectives, in this case, may be a price increase, price reduction, price maintenance, maintaining an existing product, or creating a new product [61,62].

Game theory is divided into two groups: traditional game theory and behavior-based game theory [63].

Traditional game theory has the following subgroups of game theory:

(a) Game theory based on individuality, when the parties view each other as competitors.

(b) Collaborative game theory, when the parties pursue their goals together.

Behavior-based game theory involves experimental game designs and techniques [64].

Of the two classifications of game theories, traditional game theory is the most appropriate. This can be confirmed by the fact that supply chains play an important role in international logistics, where all companies strive to retain customers and partners such that the supply chain does not stop.

In addition, collaborative game theory can be useful in identifying a factor in economic behavior, as understanding what a customer, partner, or other participants in a game is aiming for can allow for creating the game's goals and rules [65]. 
Authors state that game theory explains the balance between different economic market participants $[62,64,65]$. The international logistics market (supply chains) has a large number of different players; therefore, this theory is relevant.

Game goals and rules in international logistics can be linked to claims management strategies.

In game theory, a win-win game is an interaction in which all participants can profit in some way. In conflict resolution, a win-win strategy is a collaborative strategy and conflict resolution process. In the context of group-dynamic games, win-win games are also called "cooperative games" or "games without losers." Group-dynamic win-win games emphasize the importance of cooperation, sharing, caring, and overall group success in contrast to domination and personal gain. All players are treated as equally important and valuable. Win-win games often also carry an ethical message of caring for the environment. Win-win games are a powerful way to give people confidence, not only in themselves but also in others.

Statistical methods are science-based tools that are needed for effective management decision-making [14]. These methods must be reasonably included in the claim's settlement action.

Statistical methods have various components, with their possible uses:

1. Hypothesis evaluation-hypothesis evaluation consists of four stages: hypothesis expression, determination of the decision criteria, statistical data processing, and hypothesis evaluation [66].

2. Data collection and selection-data collection is important in that the proper analysis of the collected data can increase the quality of the service provided [67]. There are three structures for data collection: structured, semi-structured, and unstructured [68].

3. Evaluation - the evaluation of statistics is usually carried out using graphical tools [69], as large amounts of data can be processed and loaded into a chart or graph and a convenient overview of all the information transmitted by the statistics.

4. Analysis of changes. Typically, the analysis of changes is performed by determining dependencies between statistics or changing the priorities of statistics [70]. A correlation coefficient can also be assigned to the analysis of variance, as this coefficient shows the relationship of dependencies between the data.

5. Probability - probability (trend) analysis is a reliable way to find out how and why indicators change and to help predict future indicators [71]. This method of statistical analysis is valuable for predicting the outcome of future claims decisions and effecting claims resolutions.

Statistical methods can mathematically justify the handling of claims and, most importantly, do so reliably and accurately.

One of the main statistical methods is the method of probabilistic analysis. This method is for event prediction, which is relevant when managing claims. Other methods include discussion, the perception of problems, experimentation, questioning, planning, and the formation of mathematical models.

The European Union's transport market is worth 1.2 million. Private and public enterprises [72,73]. Not all of these companies are involved in international logistics, but they all face various demands for claims resolutions. Therefore, it can be concluded that one of the most important tasks of international logistics is the efficient settlement of claims in a specialized market in which thousands of companies participate.

Expert interview evaluation was used for the study. It is a procedure for reconciling the opinions of individual experts and forming a joint decision.

The methodology for reviewing expert opinions is based on the following assumptions:

- An expert has a wealth of rationally processed information and can therefore be a source of information.

- An expert group's opinion differs little from the actual solution to the problem. 
Expert evaluation is conducted in accordance with the ethical requirements of social research:

- Respondents were chosen to have sufficient competence to answer the questions.

- The consent of respondents to participate in the survey is given.

- The researcher has no influence on the respondents [74].

From all the scientific sources examined, it can be stated that the synthesis of all the tools we have presented has not yet been described, namely, blockchain systems, game theory, and statistical methods as one system for solving problems of international logistics claims management. It was therefore decided to conduct a study of expert interviews to determine whether a synthesis of these measures was possible since responses from invited experts can contribute to a better understanding of the benefits and potential of a synthesis of these tools.

A qualitative study was conducted to address two main formulated issues. With this method, it is usually possible to evaluate and visualize the answers of experts. This method was chosen because the research tasks were designed to determine the level of tools used in their direct work.

Expert interviews were developed to find out the applications of blockchain technology in solving customer claims and to find out whether the synthesis of blockchain technology with game theory and statistical methods in international logistics is possible. Managers and leading specialists of 16 of the largest international companies in Lithuania were interviewed in order to find out the latest ways of resolving claims. Requirements were set for these experts: the achievement of higher education, at least 8 years of work experience in a transport or logistics company, and experience in management positions.

Expert responses were collected in 2020 when a key element of this paper, namely, blockchain technology, was innovative and relevant. It was very important to find suitable experts for the research in all of the analyzed companies. The determination of the acceptable number of experts was based on the methodological assumptions formulated in classical test theory, which states that the reliability of aggregate decisions and the number of decision-makers (in this case, experts) is linked by a rapidly extinguishing nonlinear relationship.

Qualitative research in Lithuania is possible because there are many international logistics companies and the answers from the experts at these companies may reveal the confirmation and/or refutation of the hypotheses raised in this work. This is important because the tools described in this paper are used separately in claims management, but it is not clear at what levels and for what problems they are used by Lithuanian specialists experienced in international logistics.

The expert interviews were conducted in meetings with employees of international companies. A total of 16 experts were interviewed during the qualitative study. Experts of the largest international freight companies in Lithuania, whose work experience levels ranged from 5 to 15 years and who worked with problematic aspects of freight transport, namely, lawsuits and claims, were interviewed.

In order to find all the desired answers, this interview study presented two types of questions: questions that were relevant to the entire claims management process and questions that were more focused on the technological part of claims resolution. In most cases, the results do not provide all the answers, but highlight the main ones.

Based on the responses of the research, the consistency of opinions was assessed using the Kendall concordance calculation methodology [75]. In this way, the compatibility of expert opinions and the denial of chance were mathematically justified.

The concordance coefficient $W$ is described (when there are no related ranks) by the ratio of the calculated $S$ value:

$$
W=\frac{12 \cdot S}{n^{2} \cdot\left(m^{3}-m\right)},
$$

where $m$ is the number of criteria, $n$ is the number of experts and $S$ is the sum of the squares of the deviation from the sum of the ranks. 
When the estimates of the experts are in significant agreement, the value of the concordance coefficient $W$ is about one, but if these estimates differ to a great extent, the value of $W$ is about zero.

The concordance coefficient $W$ can be used in practice if its limiting value, showing the condition when expert estimates may be considered consistent, is determined.

Kendall and Gibbons [75] proved that when the number of criteria is $m>7$, the significance of the concordance coefficient $W$ can be determined by using Pearson's criteria (the chi-squared test).

The random value is distributed according to $\chi^{2}$ :

$$
\chi^{2}=n \cdot(m-1) \cdot W=\frac{12 \cdot S}{n \cdot m \cdot(m+1)},
$$

with the degree of freedom $v=m-1$. Based on the selected confidence level $\alpha$ (which was assumed to be 0.05 or 0.01 ), the critical value $\chi^{2}{ }_{v, \alpha}$ was found from the table of $\chi^{2}$ distribution with the degree of freedom $v=m-1$. If the value of $\chi^{2}$ calculated using Equation (2) is larger than $\chi_{v, \alpha}^{2}$, it shows that the experts' estimates are consistent.

Data from the study interviews were processed and analyzed using software.The results of the research are presented in the next section.

\section{Results}

All experts pointed to the importance of claims management in the international logistics business, and most said it was a complex day-to-day process. Furthermore, most indicated that they were looking for new management ideas and approaches in this area of management. The experts identified what skills were most needed: experience and methods.

Most experts indicated that the following model was relevant for the resolution of a claim: customer competence $\leftrightarrow$ claim settlement $\leftrightarrow$ organizational competence. Twothirds of experts indicated that claim decisions help to increase the value for all claim participants. Experts disagreed that claims management is the job of only the customer service department.

In a question about game theory, the vast majority of experts answered that they used strategies (mostly individual-based strategies) in claims management and tried to predict people's behavior.

Figure 3 shows which strategies were applied in claims management.

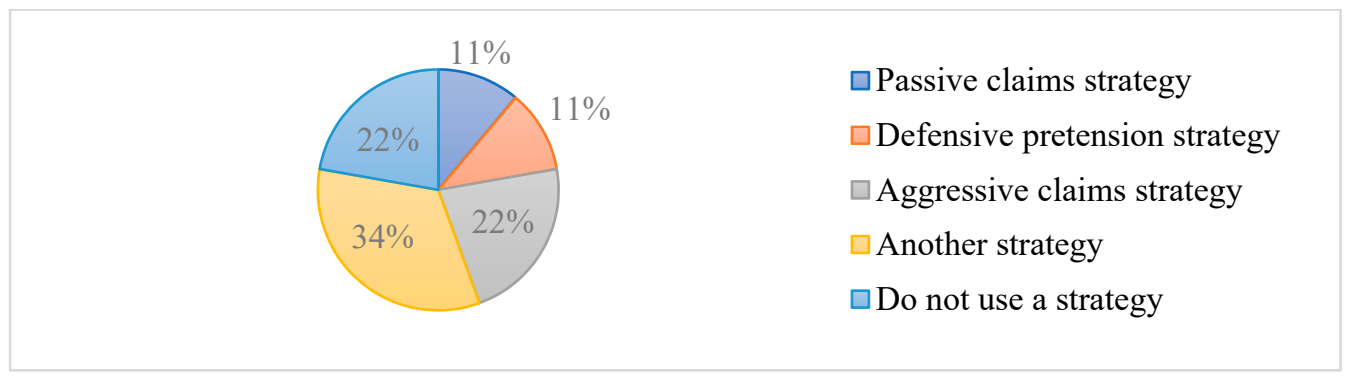

Figure 3. Strategies that were applied in claims management by the experts.

Figure 3 reveals that the majority of experts $(78 \%)$ used some form of claims management strategy. The remaining experts indicated that they did not use claims management strategies at all.

The use of statistical mathematical methods in international logistics claims management is presented in Figure 4. 


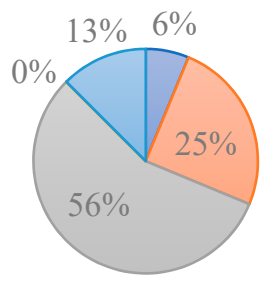

$\square$ Hypothesis evaluation

$\square$ Data collection and selection

$\square$ Evaluation

$\square$ Analysis of changes

$\square$ Probability

Figure 4. Use of statistical mathematical methods in international logistics claims management.

Figure 4 shows that the majority of all 16 experts used the estimation method (56\%), and some experts used data collection, sampling, and reliability methods together.

Figure 5 shows which of the methods mentioned in the question were most evaluated by international logistics claims management experts.

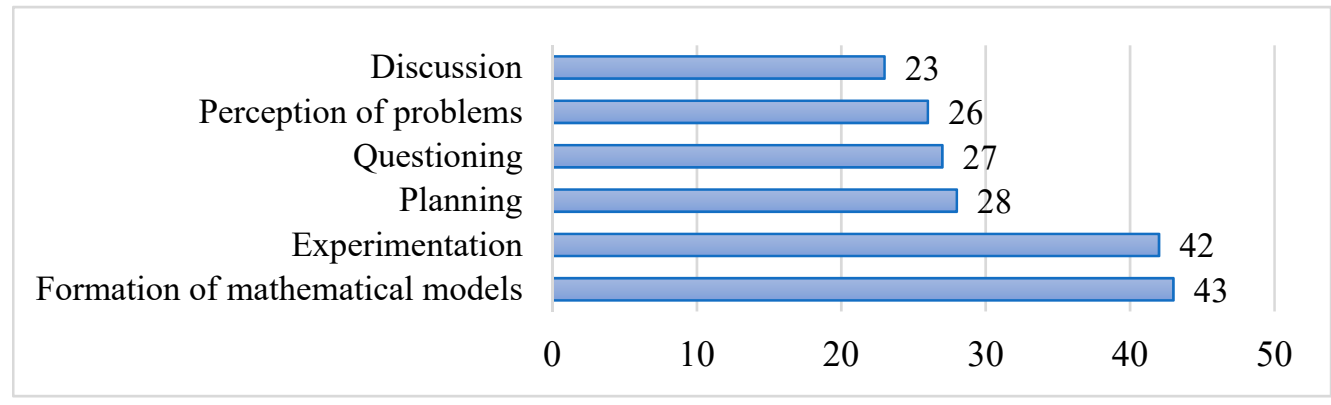

Figure 5. International logistics claims management solutions (distribution of expert opinions by rank).

The response scores of all experts were ranked as follows: 1- very significant, 10-very insignificant. Thus, the most valued were discussion, perception of problems, questioning, and planning.

The concordance coefficient equation (Equation (1)) was used to determine with certainty whether the expert opinions were harmonized and not random.

The coefficient obtained, as noted before, confirms one of the following two statements:

(a) If $\mathrm{W}=0$, then the expert opinions are contradictory.

(b) If $W \neq 0$, then the expert opinions are at least somewhat similar.

Using Equation (1), the value of $W$ was calculated: $W=0.2663$. This coefficient shows that the opinions of the experts who participated in the study of this article were somewhat similar, since $W \neq 0$. Therefore, the second statement $(W \neq 0)$ can be confirmed and the first $(W=0)$ can be rejected.

The actual value of the $\chi^{2}$ distribution is calculated below: to determine whether $W=0.2663$ is a random value, the following result was obtained using the actual $\chi^{2}$ distribution value (Equation (2)): $\chi^{2}=11.984$. Comparing the actual value of the $\chi^{2}$ distribution with the critical value $\left(\chi^{2}=0.035\right)$, it can be stated that $W=0.2663$ was not a random value. It can therefore be concluded that the expert opinions were somewhat harmonized and that their compatibility was not accidental.

Figure 6 shows the expert opinions on the key factors influencing claims management.

Based on the data in Figure 6, it can be stated that cost reduction and efficiency had the greatest impact on the management of international logistics. Absolute transparency and flexibility were slightly less influential factors, while data sustainability and integrity of operations, security, competitive advantage in resolving claims, and availability to an unlimited number of participants were less influential still. These results confirmed that the benefits of the blockchain system are important in claims management. 


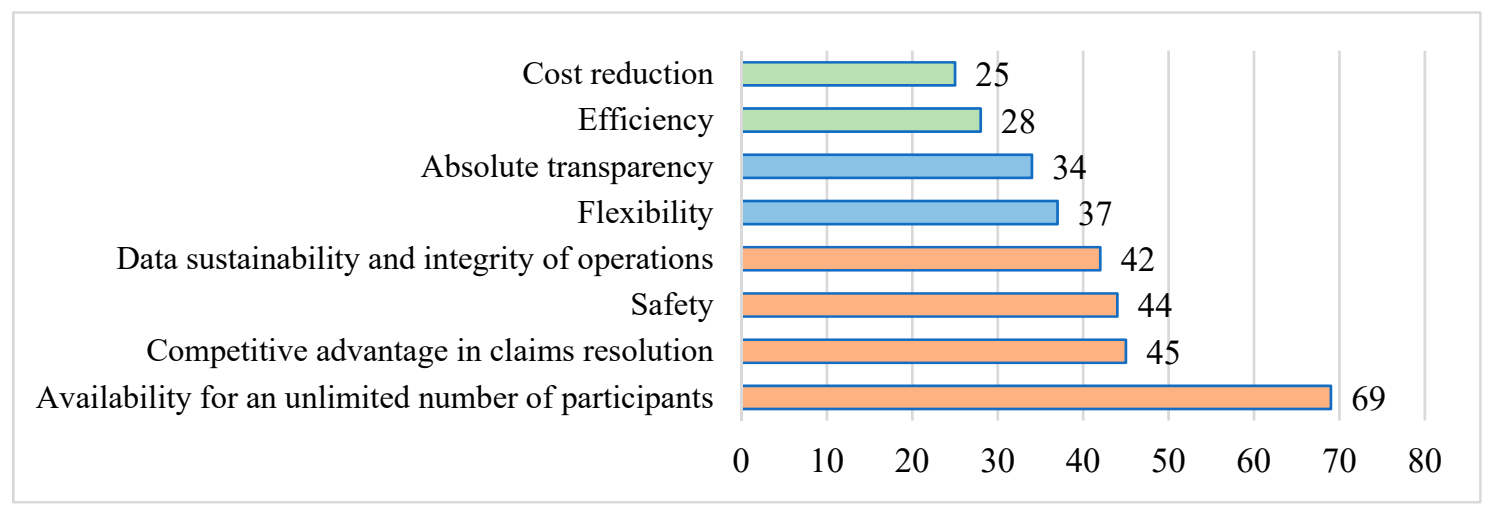

Figure 6. Factors influencing claims management (distribution of expert opinions by rank).

The main problematic claims management groups were further identified.

Figure 7 is one of the most important results from this work. The figure shows which processes were most problematic in international logistics and which were less problematic.

The evidence does not satisfy one of the negotiating parties

In the case of negotiations, one of the parties disagrees with the decision

Hostile relations between the negotiating parties

Weak negotiation skills

Calculating damage, setting repair prices and searching for additional documents takes a lot of time

Insufficient time due to high workload

Preparing a claim and filling out documents takes a lot of time

Restoration of damaged customer relations due to untimely and/or damaged cargo

Damaged cargo selection, testing, change of packaging and destruction of damaged cargo

Incomplete claims

Claims payment monitoring

Meeting with the carrier's representative and storage and sale of damaged cargo with the changed value

Negotiations are impossible without a court or arbitration

Frequent reminders about a claim

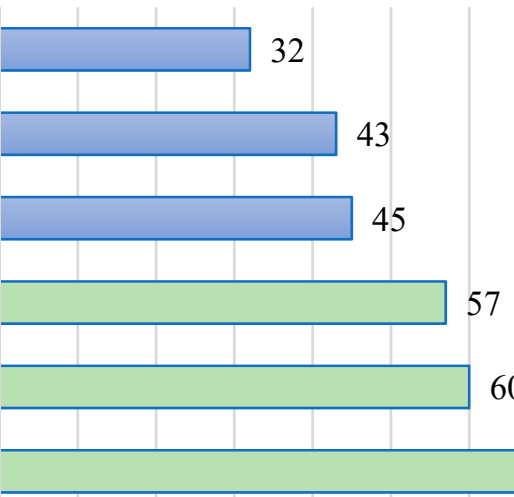
57

60

68
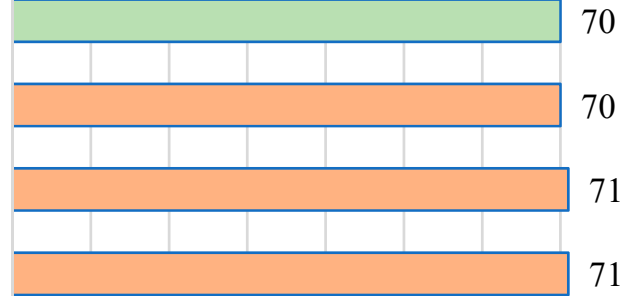

71

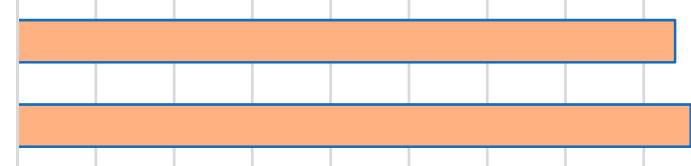

84

86

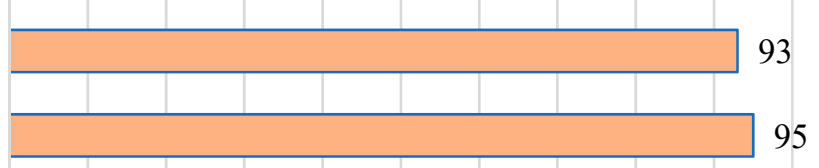

$\begin{array}{lllllllllll}0 & 10 & 20 & 30 & 40 & 50 & 60 & 70 & 80 & 90 & 100\end{array}$

Figure 7. Problem areas for resolving claims that have been identified using expert ranks (blue—group A (most problematic elements), green—group B (medium-level problem elements), orange-Group C (least problematic elements)). 
Group A (the most problematic elements) included:

- Evidence does not satisfy one of the negotiating parties.

- Disagreement by one of the parties on the decision during negotiations.

- Hostile relations between the negotiating parties.

Group B included (problematic elements at a medium level):

- Weak negotiation skills.

- Damage calculations.

- Insufficient time.

- Preparation of the claims and preparation of documents is time consuming.

Group C (least problematic elements) included the most elements:

- Restoration of damaged relationships.

- Incomplete claims.

- Claims payment monitoring.

- Reminders about the claims.

It can be said that the experts identified the following three problem areas as the most significant: the evidence does not satisfy one of the negotiating parties, the disagreement of one of the parties on the decision during negotations, and hostile relations between the negotiating parties. These three elements must be considered as the heart of the problem, without excluding the remaining eleven.

In order to determine exactly whether the expert opinions were harmonized or random, a concordance coefficient was calculated using the concordance equation (Equation (1)). This was done to confirm one of the following two statements:

(a) $\mathrm{W}=0$, expert opinions are contradictory.

(b) $\mathrm{W} \neq 0$, expert opinions are somewhat similar.

Using the concordance coefficient equation, the value of $W$ was calculated: $W=0.2492$. This coefficient shows that the opinions of the experts who participated in the study of this article were somewhat similar, since $W \neq 0$. Therefore, the second statement $(W \neq 0)$ can be confirmed and the first $(W=0)$ can be rejected.

The actual value of the $\chi^{2}$ distribution is calculated below, which was done to determine whether $W=0.2492$ was a random value using the actual $\chi^{2}$ distribution value equation (Equation (2)); the following result was obtained: $\chi^{2}=29.152$. Comparing the actual value of the $\chi^{2}$ distribution with the critical value $\left(\chi^{2}=0.0062\right)$, it can be stated that $W=0.2492$ was not a random value. It can therefore be said that the experts' opinions on this issue were somewhat harmonized and that their compatibility was not accidental.

Figure 8 shows the opinion of experts regarding solving claims management problems by applying game theory, statistical methods, and the blockchain system. Statements were made that needed to be answered "yes" or "no" to see whether a synthesis of these measures was viable.

Based on Figure 8, it can be stated that:

1. All experts agreed that the transport documents contained inaccurate data, which could give rise to a claim.

2. Only one expert noted that the company is planning to implement a blockchain system.

3. Only two experts noted that their company was planning to implement a blockchain system in supply chain processes.

4. Eight out of the sixteen experts said they recognized the blockchain system as a useful innovation for their company (50\% of all surveyed experts).

5. Twelve experts $(75 \%)$ agreed that data is important in international logistics and therefore needs to be preserved and protected from forgery.

Summarizing these statements, it can be concluded that all experts agreed with the advantages of the blockchain system but were not fully acquainted with the system itself these days. 


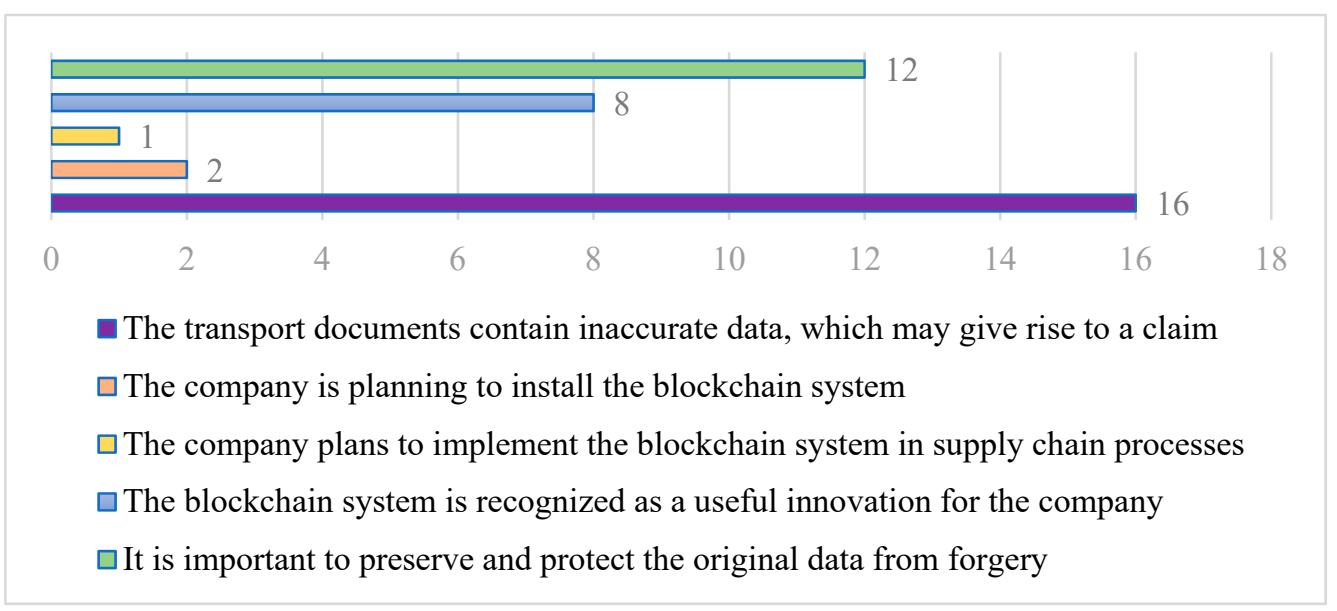

Figure 8. Expert opinion on the application of the blockchain system to resolve claims (depending on the number of experts).

Most experts in their companies felt the need for innovative claims resolution tools. Two-thirds of the experts confirmed that they were aware of the blockchain system but only $50 \%$ of all surveyed experts agreed with the statement that blockchain technology is a useful innovation for the company's operations.

All experts confirmed that the transport documents contained inaccurate data which may give rise to a claim and the importance of preserving and protecting the original data against forgery. Most experts confirmed that there are claims of improper label inspections.

The experts pointed out that the most relevant factors in claims management were cost reduction and efficiency, next was absolute transparency and flexibility, while data sustainability, security, competitive advantage in claims resolution, etc., were considered less important still.

\section{Discussion}

Given that international logistics companies feel the need for innovative claims management solutions, company executives need to be introduced to the latest claims solutions and models as much as possible, which will be based on the synthesis of blockchain technology with game theory and statistical methods.

The application of the blockchain system in international logistics is expected to provide an advantage in terms of inherent technology features, such as transparency and consistency. For example, Crosby et al. [10] and Kim et al. [46] emphasized access to critical data, as information is stored on multiple computers, providing a secure, duplicated, and synchronized ledger, i.e., for digital consignment notes that "cannot be secretly altered [... ] because the original is always visible" [76].

According to Iansiti and Lakhani [77]:

Blockchain is not a disruptive technology, which can attack a traditional business model with a lower-cost solution and overtake incumbent firms quickly. Blockchain is a foundational technology: it has the potential to create new foundations for our economic and social systems. But while the impact will be enormous, it will take decades for blockchain to seep into our economic and social infrastructure. The process of adoption will be gradual and steady, not sudden, as waves of technological and institutional change gain momentum.

The blockchain system has been described as an unreliable system [78]. This means that you do not have to trust participants in the operation that the transaction will take place due to the established algorithms, rules, and protocols in the blockchain platform. However, there are burdens and obstacles regarding whether the promises be fulfilled and what the investment requirements are for the acceptance of blockchain technology [24].

The key is the development and implementation of a blockchain system, both in the transport and logistics companies and in the customer's and third-party companies 
involved in specific shipments. This system would avoid many errors in data sustainability; in other words, the companies would be protected from incorrect information provided by the previous company. All discrepancies will be identified immediately, e.g., the load cannot be loaded until all labels have been reviewed and the corresponding value has been selected in the blockchain system. Due to the flexibility of the blockchain system, an unlimited number of such values can be created. Game management strategies based on game theory can be taken advantage of to use a number of values in a structured and dynamic way. The strategies themselves could be expanded or reduced to achieve maximum flexibility. In the event of various contingencies, it must always be possible to supplement the values of the blockchain strategies. Statistical methods are mandatory, as they provide an opportunity to analyze and optimize the blockchain system's values based on statistical and data evaluations.

The prevention of claims or the fulfillment of the conditions of claims is logical, as it ensures the solution of new or existing problem areas in international logistics, avoiding similar situations in the future and improving the quality of logistics services.

This innovative damage management system includes not only the useful features of the blockchain system but also the features of game theory and statistical methods. Summarizing these statements, it can be concluded that experts agreed with the advantages of the blockchain system, but the reality is that company employees (apart from managers) are not currently widely acquainted with the system itself and its synthesis.

The introduction to the article raised two issues: what are the possibilities of applying blockchain technology in international logistics for resolving customer claims? Is it possible to link blockchain technology to game theory and the use of statistical methods in international logistics?

After analyzing all the information provided, it can be stated that the issues raised in this work have become clear.

This study showed that it is possible to apply the synthesis of the blockchain system with game theory and statistical methods because international logistics companies face various claims management problems and blockchain features and its principles can be applied to claims management and international logistics companies' decisions in any country.

The experts identified the following three problem areas as being the most important: the evidence does not satisfy one of the negotiating parties, the disagreement of one of the parties on the decision during negotaions, and the hostile relations between the negotiating parties. These three elements must be considered as the heart of the problem.

The true distribution $\chi^{2}$ value was calculated to determine whether the concordance coefficient $W=0.2492$ was a random variable. Using the actual value of the distribution $\chi^{2}$, the following result was obtained: $\chi^{2}=29,152$. Comparing the actual distribution value with the critical value of $\chi^{2}\left(\chi^{2}=0.0062\right)$, it can be stated that $W=0.2492$ was not a random value. It can therefore be said that the experts' opinions on this issue were somewhat harmonized and that their compatibility was not accidental.

This can be justified by the fact that international logistics experts were ready to use innovative tools in claims management.

The aim of the new method is to automate claims management in international logistics by reducing the impact of human resources in this process. With this system, members of supply chains will choose strategies for cargo transportation rules (e.g., each supply chain participant must check the weight of the cargo), and the system must ensure the win-win standard of game theory. Then, after a supply participant action (e.g., weighing the cargo), the information will be automatically forwarded to other participants' systems. In the case of a claim, the responsible person will be traced immediately. In order for the information to be as reliable as possible, it must be transmitted on the basis of blockchain technology. The more this system is used, the more important the statistical methods, such as monitoring, evaluation, monitoring trends, and forecasting, will be. These methods will help to analyze existing claims and ensure the prevention of new claims. In the future, 
such a model will be available to all logistics companies such that they can control their internal processes and ensure the quality of the external processes. The automatization can be up to the next level, where in the event of a claim, a claim with all the data (including the claim template) will be generated and instantly sent to the responsible person with one click of a button.

Further claims management will also be more automatic, involving sending reminders, crediting compensation, etc. According to Manners-Bell and Lyon [13], 10\% of all lading bills contain inaccurate information. It can be argued that this proposed system will help to solve problems that arise due to incorrect filling in of consignment notes, tracing of the responsible person who filled in the consignment note incorrectly, and providing prevention by indicating the actual data and determining the meaning such that the lading bill will be updated with the actual data.

The further development of this system is an automated claims management model because, in the event of a claim, it is easy to find a discrepancy and prepare for compensation or expenses.

Benefits of using blockchain technology for claims resolution include the following:

- Time savings-For a faster and cheaper process, settlements do not require verification by a central authority.

- Cost savings-A blockchain network reduces costs since no third-party approval is required and there is a decrease in intermediaries.

- Tighter security-No one can get rid of the blockchain data because it is shared by millions of participants. The system is safe from cybercrime and fraud.

The scenario for further research may include the following:

1. Analysis of a company's internal processes in order to identify all the factors that determine the quality of cargo transportation, which would help to ensure the development of win-win strategies.

2. Analysis of the processes that occur between companies in order to identify all the factors that determine the quality of cargo transportation, which would also help to ensure the development of win-win strategies.

3. A thorough breakdown and analysis of claims to identify prevention strategies for such claims to arise.

4. Grouping and analysis of claims in order to develop long-term strategies using statistical methods.

5. Conducting surveys of the staff of international logistics companies and their customers in order to find out the current needs for win-win strategies.

\section{Conclusions}

Game theory and statistical methods are a positive complement to the blockchain system and to each other. This is the key to successful value creation for claims prevention.

International logistics companies can fully adopt an innovative claims management model and achieve better results by utilizing new innovations. Fifty percent of all experts surveyed said that they recognized the blockchain system as a useful innovation for their business, and as many as $75 \%$ agreed that it was important to preserve and protect data from being counterfeited in international logistics.

The blockchain system, together with game theory and statistical methods, can be applied in the management of international logistics claims, as companies feel the need for innovative tools and already know about and can start implementing the blockchain system.

The blockchain system is integrated into international logistics but this system is not yet popular in claims management. This system is promising for management and has many advantages that are required in today's international logistics for claims management and claims resolutions.

This qualitative study found that experts from international logistics companies subconsciously, but not fully, use game theory in claims management. The blockchain system is partially known to them, but so far, they do not plan to install this system 
soon. The answers of the experts to the additional questions revealed that the synthesis of these measures would be useful in their activities due to the advantages provided by the measures and the desire to innovate in this part of management.

During the interviews with experts, it was clarified which methods of claim resolution were the most relevant in international logistics, namely, discussion, the understanding of problems, questioning, and planning.

Using the concordance coefficient formula, the value of $W$ was calculated: $W=0.2663$. This ratio indicates that the opinions of the experts who participated in this study were somewhat similar. The value of the actual $\chi^{2}$ distribution was also calculated and the following result was obtained: $\chi^{2}=11.984$. Comparing the actual value of the distribution with the critical value $\left(\chi^{2}=0.035\right)$, it can be stated that $W=0.2663$ was not a random value. It can therefore be concluded that the experts' opinions were somewhat harmonized and that their compatibility was not accidental.

Given that international logistics companies have not yet started implementing the blockchain system and do not yet use either game theory or the synthesis of statistical methods when resolving claims, the analysis of the interview responses suggested that claims management could be improved. International logistics experts are ready to use innovative claims management tools.

The biggest benefits of implementing blockchain technology in transportation organizations and supply chains are higher data and transaction speeds, improved security of the shared data, digitized documents, and a reduced number of intermediaries.

By using the tools of game theory and statistical methods together with the blockchain system, international logistics companies could reduce their costs, speed up the management process, and increase data security and reliability. The consequence of this whole process is the improvement of the cooperation of the international logistics community, the increase of operational efficiency, and technological competitiveness.

There have been many unsuccessful attempts to use blockchain technology around the world, as well as many successful business cases. Emerging technology blockchains are expected to find their place in practice and become widely recognized for dealing with block circuit cases. The latter takes a rather optimistic view that as more progress is made in addressing the constraints of block circuits, as with many other emerging technologies, block circuits will find their place in practice and become widely accepted.

International logistics claims management should use today's technological advances, namely, the blockchain system in conjunction with other methods, to ensure structured, onestop claims management. By using the synthesis of the blockchain system in combination with game theory and statistical methods, international logistics companies could reduce their costs, speed up the management process, and increase data security and reliability.

Author Contributions: Conceptualization, N.B. and M.M.; methodology, M.M.; validation, N.B. and M.M.; formal analysis, N.B.; investigation, M.M.; resources, N.B.; data curation, N.B.; writingoriginal draft preparation, N.B.; writing-review and editing, N.B. and M.M.; visualization, N.B.; supervision, N.B.; project administration, N.B. and M.M.; funding acquisition, N.B. All authors have read and agreed to the published version of the manuscript.

Funding: This research was funded by Vilnius Gediminas Technical University.

Institutional Review Board Statement: Not applicable.

Informed Consent Statement: Not applicable.

Data Availability Statement: Not applicable.

Conflicts of Interest: The authors declare no conflict of interest.

\section{References}

1. Brand, S. Supply Chain Management and Logistics: What's the Difference. 2020. Available online: https://www.cmtc.com/blog/ supply-chain-management-and-logistics-whats-the-difference (accessed on 14 January 2021).

2. $\quad$ Palšaitis, R. Tarptautinio Verslo Transportinis Logistinis Aptarnavima; Technika: Vilnius, Lithuania, 2011; p. 288. 
3. Griffiths, C.; Costi, M. The Creative Thinking Handbook: Your Step-by-Step Guide to Problem Solving in Business. 2019. Available online: https://www.amazon.com/Creative-Thinking-Handbook-Step-Step-ebook/dp/B07Q2ZBT1H (accessed on 25 January 2021).

4. Dobrovnik, M.; Herold, D.M.; Fürst, E.; Kummer, S. Blockchain for and in Logistics: What to Adopt and Where to Start. Logistics 2018, 2, 18. [CrossRef]

5. Gremyr, I.; Elg, M.; Hellström, A.; Martin, J.; Witell, L. The roles of quality departments and their influence on business results. Total. Qual. Manag. Bus. Excel. 2019, 1-12. [CrossRef]

6. Ramon, J.; Mateo, S.C. Management Science, Operations Research and Project Management: Modelling, Evaluation, Scheduling, Monitoring; Routledge: London, UK, 2016; p. 234.

7. Ross, D.F. Introduction to e-Supply Chain Management: Engaging Technology to Build Market-Winning Business Partnerships; CRC Press: Boca Raton, FL, USA, 2002; p. 384.

8. What Is an Analytical Framework? 2018. Available online: https://deephelp.zendesk.com/hc/en-us/articles/360006969651-Wh at-is-an-Analytical-Framework (accessed on 10 January 2021).

9. AmishGupta. Introduction to BLOCKCHAIN Technology: Set 1. 2019. Available online: https://www.geeksforgeeks.org/blockc hain-technology-introduction/ (accessed on 13 January 2021).

10. Crosby, M.; Pattanayak, P.; Verma, S.; Kalyanaraman, V. Blockchain technology: Beyond bitcoin. Appl. Innov. Rev. 2016, 2, 6-10.

11. Vigliotti, M.G.; Jones, H. The Executive Guide to Blockchain: Using Smart Contracts and Digital Currents in Your Business; Springer Nature: Berlin/Heidelberg, Germany, 2020; p. 193.

12. Pagano, A.M.; Liotine, M. Technology in Supply Chain Management and Logistics: Current Practice and Future Applications; Elsevier: Amsterdam, The Netherlands, 2019; p. 220.

13. Manners-Bell, J.; Lyon, K. The Logistics and Supply Chain Innovation Handbook: Disruptive Technologies and New Business Models; Kogan Page Publishers: London, UK, 2019; p. 280.

14. Keller, G. Statistics for Management and Economics + XLSTAT Bind-in; Cengage Learning: Boston, MA, USA, 2017 ; p. 992.

15. O'Brien, J. Negotiation for Procurement Professionals: A Proven Approach that Puts the Buyer in Control; Kogan Page Publishers: London, UK, 2016; p. 440.

16. O'Neill, C. Everybody's Guide to Small Claims Court; Nolo: Berkeley, CA, USA, 2020; p. 432.

17. Jethu-Ramsoedh, R.; Hendrickx, M. International Business; Routledge: London, UK, 2019; p. 324.

18. Waters, D. Global Logistics and Distribution Planning: Strategies for Management; Routledge: London, UK, 2018 ; p. 416.

19. Giffen, P. How Blockchain Will Change Projects Management. Monday Project. 2019. Available online: https://monday.com/blo $\mathrm{g} /$ blockchain-will-change-project-management/ (accessed on 10 October 2020).

20. Kimmons, R.L.; Loweree, J.H. Project Management: A Reference for Professionals; Routledge: London, UK, 2017 ; p. 1136.

21. Volkmar-Jaeger, A.; Sebastian-Hok, G. FIDIC-A Guide for Practitioners; Springer Science \& Business Media: Berlin/Heidelberg, Germany, 2009; p. 446.

22. Garrette, B.; Phelps, C.; Sibony, O. Cracked It! How to Solve Big Problems and Sell Solutions Like Top Strategy Consultants; Springer: Berlin/Heidelberg, Germany, 2018; p. 284.

23. Iron Mountain Incorporated (NYSE: IRM). What Is Blockchain and Why Should Records Management Professionals Care? 2020. Available online: https: / www.ironmountain.com/resources/general-articles / w / what-is-blockchain-and-why-should-reco rds-management-professionals-care (accessed on 18 November 2020).

24. Saberi, S.; Kouhizadeh, M.; Sarkis, J.; Shen, L. Blockchain technology and its relationships to sustainable supply chain management. Int. J. Prod. Res. 2019, 57, 2117-2135. [CrossRef]

25. Pournader, M.; Shi, Y.; Seuring, S.; Koh, S.L. Blockchain applications in supply chains, transport and logistics: A systematic review of the literature. Int. J. Prod. Res. 2019, 58, 2063-2081. [CrossRef]

26. Dolgui, A.; Ivanov, D.; Potryasaev, S.; Sokolov, B.; Ivanova, M.; Werner, F. Blockchain-oriented dynamic modelling of smart contract design and execution in the supply chain. Int. J. Prod. Res. 2020, 58, 2184-2199. [CrossRef]

27. Underwood, S. Blockchain beyond bitcoin. Commun. ACM 2016, 59, 15-17. [CrossRef]

28. Di Vaio, A.; Varriale, L. Blockchain technology in supply chain management for sustainable performance: Evidence from the airport industry. Int. J. Inf. Manag. 2020, 52, 102014. [CrossRef]

29. Yang, C.-S. Maritime shipping digitalization: Blockchain-based technology applications, future improvements, and intention to use. Transp. Res. Part E: Logist. Transp. Rev. 2019, 131, 108-117. [CrossRef]

30. Kumar, A.; Liu, R.; Shan, Z. Is Blockchain a Silver Bullet for Supply Chain Management? Technical Challenges and Research Opportunities. Decis. Sci. 2020, 51, 8-37. [CrossRef]

31. Kouhizadeh, M.; Sarkis, J.; Zhu, Q. At the Nexus of Blockchain Technology, the Circular Economy, and Product Deletion. Appl. Sci. 2019, 9, 1712. [CrossRef]

32. Koh, L.; Dolgui, A.; Sarkis, J. Blockchain in transport and logistics-paradigms and transitions. Int. J. Prod. Res. 2020, 58, 2054-2062. [CrossRef]

33. Kouhizadeh, M.; Zhu, Q.; Sarkis, J. Blockchain and the circular economy: Potential tensions and critical reflections from practice. Prod. Plan. Control. 2019, 31, 950-966. [CrossRef]

34. Kouhizadeh, M.; Sarkis, J. Blockchain Practices, Potentials, and Perspectives in Greening Supply Chains. Sustainability 2018, 10, 3652. [CrossRef] 
35. Choi, T.-M.; Guo, S.; Liu, N.; Shi, X. Optimal pricing in on-demand-service-platform-operations with hired agents and risksensitive customers in the blockchain era. Eur. J. Oper. Res. 2020, 284, 1031-1042. [CrossRef]

36. Jung, S.; Krebs, P. The Essentials of Contract Negotiation; Springer: Berlin/Heidelberg, Germany, 2019 ; p. 242.

37. Calvello, M. Statistical Analysis: A Better Way to Make Business Decisions. 2020. Available online: https://learn.g2.com/statistic al-analysis (accessed on 1 October 2020).

38. Waller, M.A.; Hoek, R.; Davletshin, M.; Fugate, B. Integrating Blockchain into Supply Chain Management: A Toolkit for Practical Implementation; Kogan Page Publishers: London, UK, 2019; p. 264.

39. Wiley, J.; Carruthers, C. Data Driven Business Transformation: How to Disrupt, Innovate and Stay Ahead of the Competition; John Wiley \& Sons: Hoboken, NJ, USA, 2019; p. 288.

40. Collins, D. 5 Questions You Should Ask about Your Claims Management Process. 2020. Available online: https://cloudhub360. com/5-questions-you-should-ask-about-your-claims-management-process / (accessed on 10 March 2020).

41. Robinson, A. Freight Claims Management Trends for 2020: Why Freight Claims Will Decrease Thanks to Proactiveness. 2020. Available online: https:/ / cerasis.com/freight-claims-management-trends/ (accessed on 10 March 2020).

42. Freight Claims Management: A Guide to Mitigate, File and Resolve. 2020. Available online: https://mercurygate.com/blog/fre ight/freight-claims-management-guide-to-mitigate-file-and-resolve/ (accessed on 10 March 2020).

43. Stamatiou, D.R.I.; Kirytopoulos, K.A.; Ponis, S.T.; Gayialis, S.; Tatsiopoulos, I. A process reference model for claims management in construction supply chains: The contractors' perspective. Int. J. Constr. Manag. 2019, 19, 382-400. [CrossRef]

44. Mahankali, S. Blockchain: The Untold Story: From Birth of Internet to Future of Blockchain; BPB Publications: Noida, India, 2019; p. 395.

45. Krishnan, S.; Balas, V.E.; Golden, J.; Robinson, H.Y.; Balaji, S.; Kumar, R. Handbook of Research on Blockchain Technology; Academic Press: Cambridge, MA, USA, 2020; p. 476.

46. Kim, H.M.; Laskowski, M. Toward an ontology-driven blockchain design for supply-chain provenance. Int. J. Intell. Syst. Account. Financ. Manag. 2018, 25, 18-27. [CrossRef]

47. Johnson, D. How to Navigate Claims Negotiations. Claims Journal. 19 April 2011. Available online: https://www.claimsjournal. com/news/national/2011/04/19/184423.htm (accessed on 15 July 2020).

48. Greenhalgh, B. Introduction to Construction Contract Management; Routledge: London, UK, 2016; p. 236.

49. Volovoj, V. Kas žinotina, gavus pretenzija. Cargonews. 2017. Available online: https://www.cargonews.lt/aktualijos/ka-turetum ete-ivertinti-gave-pretenzija-teisininkes-komentaras / (accessed on 5 January 2021).

50. Robinson, A. Effective Freight Claim Management: Decrease Time on These 7 Freight Claim Time Wasters. 2018. Available online: https: / / cerasis.com/ freight-claim-management/ (accessed on 15 July 2020).

51. Richards, G.; Grinsted, S. The Logistics and Supply Chain Toolkit: 100 Tools and Guides for Supply Chain, Transport, Warehousing and Inventory Management; Kogan Page Publishers: London, UK, 2016; p. 400.

52. Bakhary, N.A.; Adnan, H.; Ibrahim, A. A Study of Construction Claim Management Problems in Malaysia. Procedia Econ. Financ. 2015, 23, 63-70. [CrossRef]

53. Tambunan, H. The Effectiveness of the Problem Solving Strategy and the Scientific Approach to Students' Mathematical Capabilities in High Order Thinking Skills. Int. Electron. J. Math. Educ. 2019, 14, 293-302. [CrossRef]

54. Tapscott, D.; Tapscott, A. Blockchain Revolution: How the Technology Behind Bitcoin Is Changing Money, Busines, and the World; Reprint Edition; Kindle Edition; Portfolio: London, UK, 2016; p. 365, ISBN-13: 978-1101980149, ISBN-10: 1101980141.

55. Chong, A.Y.; Lim, T.; Hua, X.; Zheng, S.; Tan, C.W. Business on Chain: A Comparative Case Study of Five Blockchain-Inspired Business Models. J. Assoc. Inf. Syst. 2019, 20, 9. [CrossRef]

56. Nowiński, W.; Kozma, M. How Can Blockchain Technology Disrupt the Existing Business Models? Entrep. Bus. Econ. Rev. 2017, 5, 173-188. [CrossRef]

57. Hastig, G.M.; Sodhi, M.S. Blockchain for Supply Chain Traceability: Business Requirements and Critical Success Factors. Prod. Oper. Manag. 2019, 29, 935-954. [CrossRef]

58. Dam, R.F.; Yu Siang, T. 5 Stages in the Design Thinking Process. Interaction Design Foundation. 2020. Available online: https: / / www.interaction-design.org/literature/article/5-stages-in-the-design-thinking-process (accessed on 10 October 2020).

59. Du Preez, O. Conciliation: A Founding Element in Claims Management. Procedia Soc. Behav. Sci. 2014, 119, 115-123. [CrossRef]

60. Chadha, A. Game Theory for Managers; PHI Learning Pvt. Ltd.: Delhi, India, 2015; p. 256.

61. Game Theory. Economics Online. 2020. Available online: https://www.economicsonline.co.uk/Business_economics/Prisoners _dilemma.html (accessed on 10 October 2020).

62. Das, S.M. Game Theory 101 for Dummies Like Me. 2019. Available online: https://books-online.club/sl-SNSZH-D7256/signupblitz/\#/z=gU7AeONoCaUDmNjpaJObHy/theme=default/q=game+theory+101+for+dummies+like+me+by+sangeet+moy+ das $/$ s1=/s2=/s3=/s4=/s5=/source_id=116965ad-f99c-9f01-8604-97e8aaab6b83/project=pq6sdt/mh_offer_id=/dp=eXjMeGK 2p6siXFPdzm8kss/m=/c_bg=/c_img1=/c_img2=/c_color=/source=Referral/software=Browser /domain=cdn.bkfd4.club / (accessed on 10 June 2020).

63. Bonau, S. A Case for Behavioural Game Theory. J. Game Theory 2017, 6, 7-14. [CrossRef]

64. Joseph, E. What Is Game Theory? 2017. Available online: https://blog.oup.com/2017/05/game-theory-facts/ (accessed on 10 October 2020).

65. Samuelson, L. Game Theory in Economics and Beyond. J. Econ. Perspect. 2016, 30, 107-130. [CrossRef] 
66. Privitera, G.J. Statistics for the Behavioral Sciences; SAGE Publications: Thousand Oaks, CA, USA, 2017 ; p. 816.

67. Jovancic, N. 5 Data Collection Methods for Obtaining Quantitative and Qualitative Data. 2019. Available online: https: //www.leadquizzes.com/blog/data-collection-methods / (accessed on 1 October 2020).

68. Gill, P.; Stewart, K.; Treasure, E.; Chadwick, B. Methods of data collection in qualitative research: Interviews and focus groups. Br. Dent. J. 2008, 204, 291-295. [CrossRef]

69. Brown, T. Design Thinking. 2020. Available online: https://www.ideou.com/pages/design-thinking (accessed on 1 October 2020).

70. Jayatilleke, S.; Lai, R.; Reed, K. A method of requirements change analysis. In Requirements Engineering; Springer: Berlin/Heidelberg, Germany, November 2018. [CrossRef]

71. Chataigner. What Is an Analytical Framework? 2017. Available online: https://deephelp.zendesk.com/hc/en-us/articles/36000 6969651-What-is-an-Analytical-Framework- (accessed on 10 October 2020).

72. Eurostat Statistics Explained. People Who Have a Tertiary Education and Work in a Science and Technology Occupation, 2012 and 2019 (\% Share of Active Population Aged 15-74). Available online: https:/ / ec.europa.eu/eurostat/statistics-explained/ind ex.php?title=File:People_who_have_a_tertiary_education_and_work_in_a_science_and_technology_occupation,_2012_and_2 019_(\%25_share_of_active_popuation_aged_15-74).png (accessed on 10 October 2020).

73. Transport in the European Union. Current Trends and Issues. In Mobility and Transport; European Commission: Luxembourg, March 2019; Available online: https:/ / ec.europa.eu/transport/sites/transport/files/2019-transport-in-the-eu-current-trends-a nd-issues.pdf (accessed on 10 May 2020).

74. Kardelis, K. Moksliniu Tyrimu Metodologija ir Metodai Vadovelis, 3rd ed.; Lucilijus: Šiauliai, Lithuania, 2005; p. 398.

75. Kendall, M.; Gibbons, J.D. Rank Correlation Methods, 5th ed.; Oxford University Press: Oxford, UK, $1990 ;$ p. 260.

76. Morley, H.R. Industry Skeptical of Pace of Logistics Tech Adoption. In International Logistics; JOC: New York, NY, USA, 2017.

77. Iansiti, M.; Lakhani, K.R. The Truth about Blockchain. Harvard Business Review. 2017. Available online: https://enterprisersproj ect.com/sites/default/files/the_truth_about_blockchain.pdf. (accessed on 24 February 2021).

78. Cole, R.; Stevenson, M.; Aitken, J. Blockchain technology: Implications for operations and supply chain management. Supply Chain Manag. Int. J. 2019, 24, 469-483. [CrossRef] 